\title{
Uncertainty Analysis on Global Greenhouse Gas Inventories from Anthropogenic Sources
}

\author{
Richao Cong, Makoto Saito, Ryuichi Hirata, Akihiko Ito, Shamil Maksyutov \\ National Institute for Environmental Studies \\ 16-2 Onogawa, Tsukuba, Ibaraki, Japan \\ Richao.cong@nies.go.jp; Saito.makoto@nies.go.jp; hirata.ryuichi@nies.go.jp; itoh@nies.go.jp; shamil@nies.go.jp
}

\begin{abstract}
As the concerns on climate change increased, accurately quantifying the greenhouse gas (GHG) emissions from anthropogenic sources has been emphasized more and more. In this paper, uncertainty analysis is conducted for multiple global GHG inventories from anthropogenic sources to explore the sources and the magnitude of them. We first summarize the principal characteristic for 17 global GHG inventories by four indexes. And then to assess the sources and magnitude of uncertainties for these inventories, the discrepancies are quantified on energy statistics data and estimation results of carbon dioxide $\left(\mathrm{CO}_{2}\right)$ emission on anthropogenic sources at the global total and national scale. Finally, we determine the nations with larger magnitude (extent and proportion) of uncertainties by two indicators which will be helpful for the policy-making on GHG emissions mitigation. As the analysis result, we find that uncertainty of oil consumption data is the largest among major fuels in 2013 as much as 44.6 exajoules (EJ) and the magnitude of uncertainty in $\mathrm{CO}_{2}$ emissions data is significant at global perspective as much as 4.0 petagrams $(\mathrm{Pg}) \mathrm{CO}_{2}$ $\mathrm{yr}^{-1}$. At national perspective, as the largest emitter nation in 2013 China, uncertainty from the coal consumption data of which is the largest in major fuels as much as $15.5 \mathrm{EJ}$ and the magnitude of uncertainty for $\mathrm{CO}_{2}$ emissions of China in 2013 is as much as 1.5 $\mathrm{Pg} \mathrm{CO}_{2} \mathrm{yr}^{-1}$.
\end{abstract}

Keywords: GHG Inventory, $\mathrm{CO}_{2}$ Emissions, Uncertainty Analysis, Anthropogenic Source.

\section{Introduction}

The current rise in atmospheric carbon dioxide $\left(\mathrm{CO}_{2}\right)$ concentration due to anthropogenic emissions is the single largest contributor to modern climate change. Reducing anthropogenic emissions is therefore crucial for climate change mitigation, and individual nations need to both quantify their greenhouse gases (GHG) emissions, including gases other than $\mathrm{CO}_{2}$, and monitor the effects of mitigation policies. National GHG inventory documents a country's GHG sources and sinks over the course of a year. As it could track the change of anthropogenic emissions, inventory is considered as a useful tool for scientific use. Furthermore, it could also provide quantitative reference to support the policy-making on climate change.

Under the UN Framework Convention on Climate Change (UNFCCC), Annex I parties (developed countries) are required to submit annual inventories of anthropogenic GHG emissions from sources and their removal by sinks. Furthermore, the Intergovernmental Panel on Climate Change (IPCC) Guidelines for National Greenhouse Gas Inventories [1] were issued in 2006 as an internationally agreed framework for estimating GHG inventories, numerous nations have made efforts to contribute in this global issue. As the absences of some nations, other global GHG inventories have to be relied on when the policy-making and scientific use are conducted at global scale. Consequently, there are numerous global GHG inventories currently available (e.g., datasets from the Carbon Dioxide Information Analysis Center (CDIAC) [2], Emissions Database for Global Atmospheric Research (EDGAR) [3], and International Energy Agency (IEA) [4]), each based on a different methodology and/or compilation procedure. How about the discrepancies of emissions values between these databases?

In figure 1, we show the discrepancies in national $\mathrm{CO}_{2}$ emissions reported by 11 global GHG inventories for 131 nations in 2008. Outlier could be as high as about $250 \%$ and the uncertainties from small emitter nations seem higher than that from the larger ones. Estimated global GHG inventories include a degree of uncertainty, and in his analysis of four independent datasets, Macknick documented significant discrepancies in energy-use statistics and accounting methods. For example, the international energy content reported by British Petroleum (BP) in 2005 differs from that provided by the US Energy Information Administration (EIA) by $11 \%$, or 18 exajoules (EJ). Similarly, estimates by the EIA and CDIAC of $\mathrm{CO}_{2}$ emissions for the United States in 2005 differ by $>0.22$ petagrams $(\mathrm{Pg}) \mathrm{CO}_{2}[5]$. 


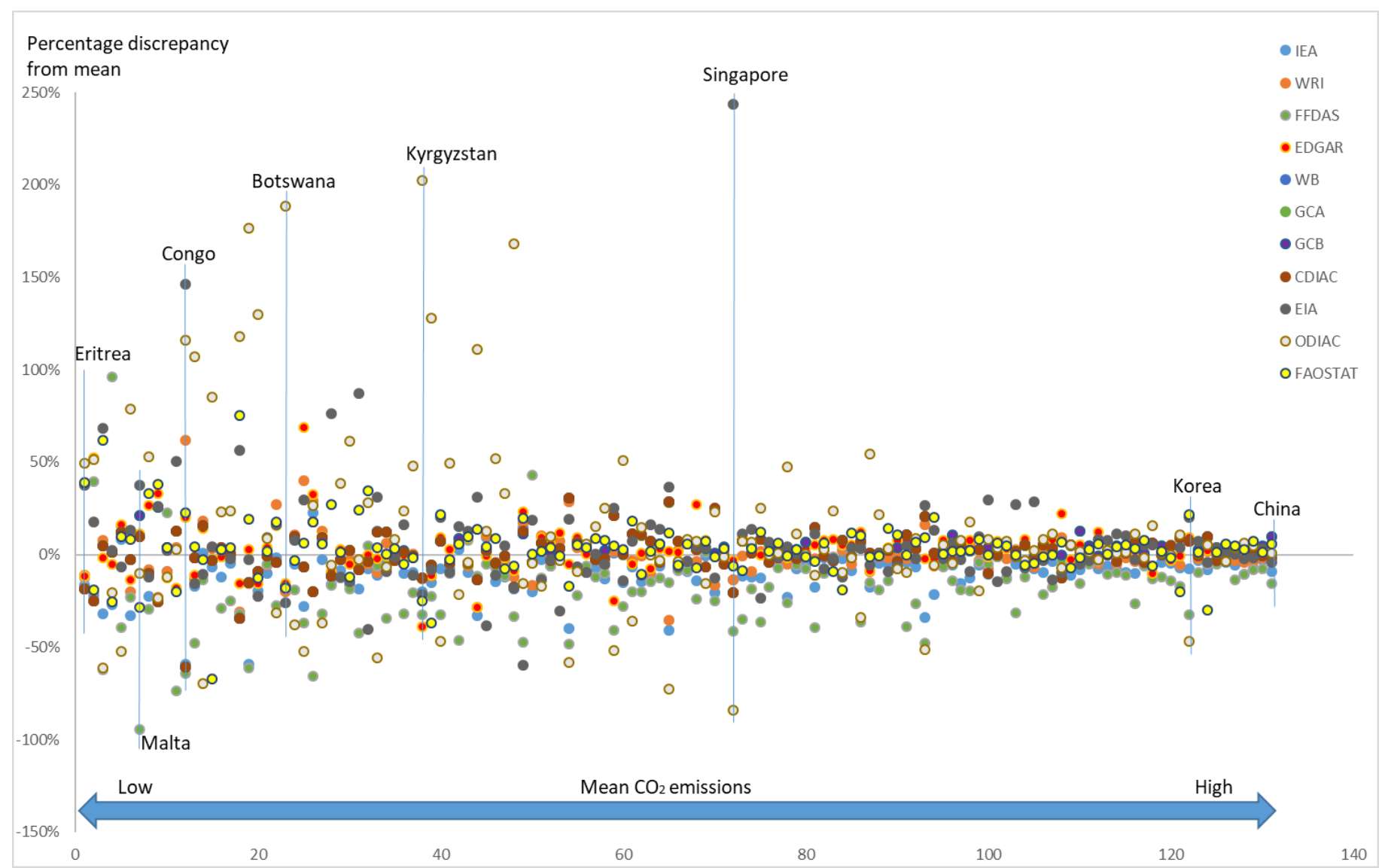

Fig. 1: Discrepancies in total emissions reported by 11 inventories (the names are showed on the right) for 131 nations in 2008 . The nations are spread along the $\mathrm{x}$-axis according to their rank-order of mean $\mathrm{CO}_{2}$ emissions as reported in the respective datasets. Points around zero on the $\mathrm{y}$-axis reflect the differences among the total emissions reported.

Under the Kyoto Protocol, the emissions reduction target set by EU15 members for the period 2008-2012 is 8\% below 1990 levels [6]. If there is a large uncertainty containing in the GHG inventory, it would disturb evaluating the reduction effect so that the credibility of the evaluation will decrease. Thus, clarifying the sources of uncertainty and evaluating the magnitude of uncertainties in recent global GHG inventories are urgently needed.

With these background, the objectives of this paper are made to clarify the sources and magnitude of uncertainties in multiple global GHG inventories. To do this, we first characterize the methodology and data sources of 17 GHG inventories. Then, we explore the discrepancies on data source used for estimation (energy statistics data by fuel types) and datasets (annual estimation result for some nations).

\section{Methodology}

In this study, 17 global GHG inventories are collected and characterized by four indexes. To explore the uncertainties from these inventories, comparisons are focused on the energy statistics data by fuel types and the estimation result at global and national scale in 2013. Furthermore, the nations with larger uncertainties are determined by two indicators.

\subsection{Characteristics of the Principal Datasets in Global GHG Inventories}

As shown in Table 1, these inventories are classified by the indexes of time series, scope, data source, and data description. For data source index, most inventories rely on statistical data provided by the United Nations (UN), IEA, EIA, and BP. We note, however, that even when the same data are used, the total emissions of a given nation or sector can vary depending on the statistics rules used (e.g., report integrity, classification rules, conversion factors for calorific content). Further uncertainty results from the incorporation of different emissions factors and accounting methods, as well as the subjective classification of emission categories by reporting organizations. The quality of emissions inventories is considered to rely on the integrity of the methodology used, completeness of reporting, and the procedures employed for data compilation. 
Table 1: Characteristics of 17 GHG inventories by four indexes.

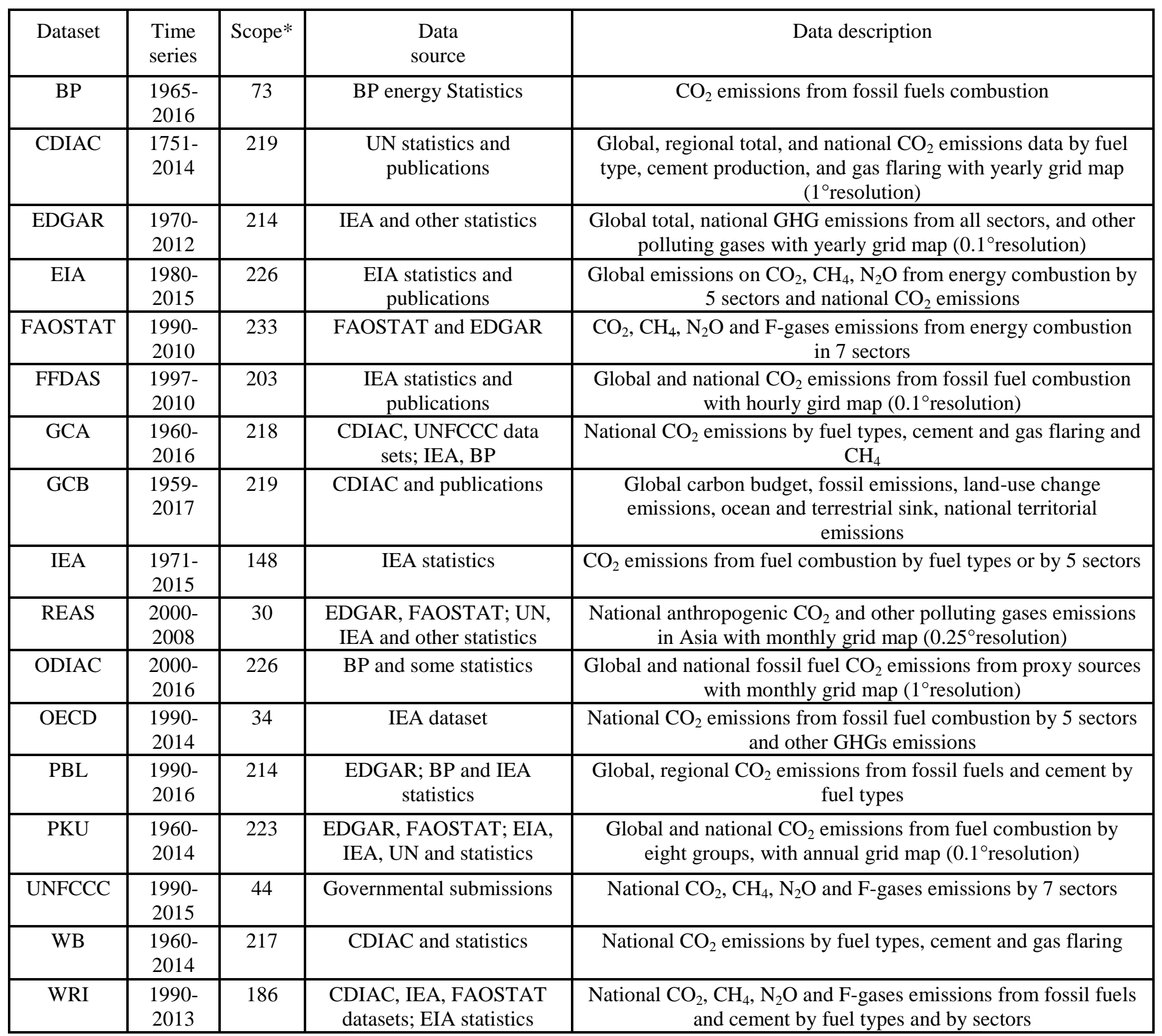

*Note: Several values included in the table are derived from the accessible websites of the respective inventories, while others have been counted by the authors from the datasets. The abbreviations of datasets are explained as follows:

FAOSTAT: Food and Agriculture Organization Corporate Statistics Database [7]

FFDAS: Fossil Fuel Data Assimilation System [8]

GCA: Global Carbon Atlas [9]

GCB: Global Carbon Budget [10]

REAS: Regional Emission inventory in Asia [11]

ODIAC: Open-source Data Inventory of Anthropogenic $\mathrm{CO}_{2}$ emission [12]

OECD: Organisation for Economic Co-operation and Development [13]

PBL: Planbreau voor de Leefomgeving [14]

PKU: Peking University Fuel and $\mathrm{CO}_{2}$ inventories [15]

WB: World Bank [16] 
WRI: World Resources Institute [17]

\subsection{Uncertainties from Energy Statistics Data}

To access the discrepancies from the energy data sources, apparent energy consumption data of global total and the largest consumer nation of China by fuel types in 2013 are compared between four main energy statistics organizations. The apparent energy consumption data are extracted and summarized from the online statistics tool [18-19], energy statistics yearbook [20] and annual report [21].

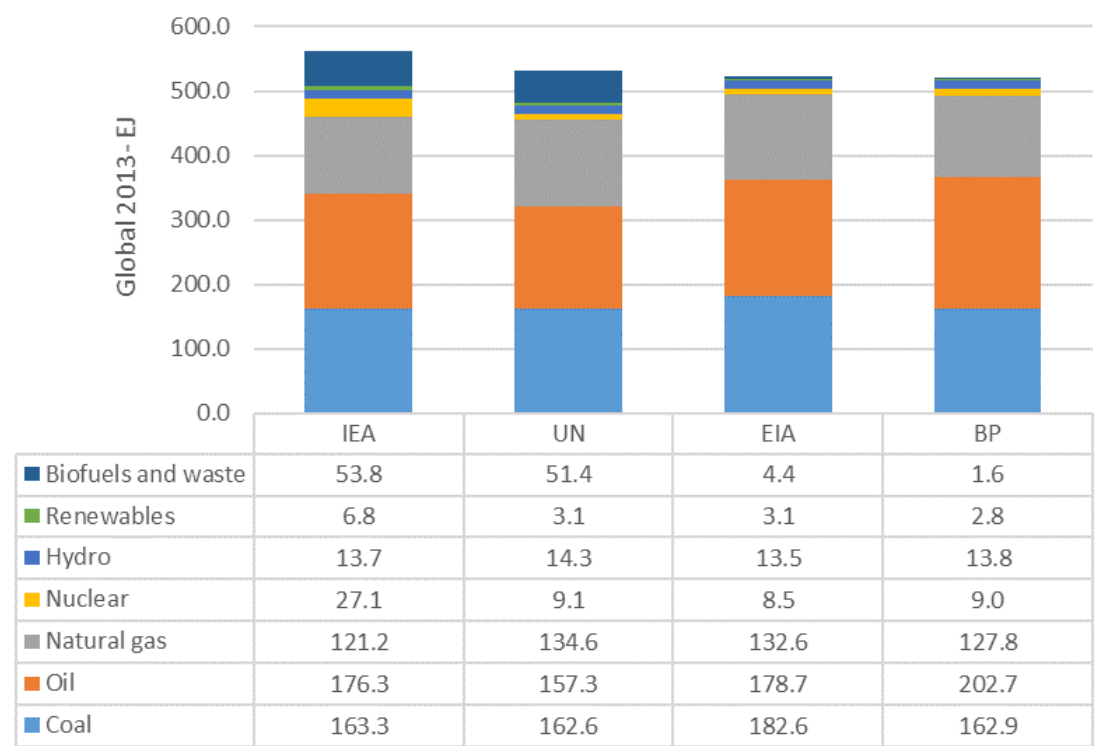

Fig. 2: Global total apparent energy consumption by fuel types.

As shown in figure 2, from the global perspective, the global total consumption in 2013 from IEA statistics is the largest of all. In particularly, nuclear, renewables and biofuels \& waste consumption values from IEA are larger than that from others. Most of the statistics values from UN are close to IEA except nuclear and oil consumption. EIA has reported the largest coal consumption data among them. BP statistics just reports the commercial energy use therefore the total value of which is the smallest. However, the oil consumption from BP is the largest one. The gap between maximum (IEA) and minimum (BP) of global total energy consumption is about 24.3 EJ. The global total biofuels \& waste consumption owned the largest uncertainty (52.2 EJ between IEA and BP) of all fuels because commercial fuels only reported by BP. Focusing on three main fuels, oil consumption owns the largest uncertainty of all that is about 44.6 EJ between BP and UN. From national view as shown in figure 3, nuclear, renewables and the largest biofuels \& waste consumption data reported for China in 2013 by IEA are larger than that by others. The oil, coal consumption and the total values from EIA are the largest of all. The gap on total energy consumption of China in 2013 between maximum (EIA) and minimum (UN) is about 18.7 EJ. The uncertainty of coal consumption is the largest $(15.5 \mathrm{EJ})$ of all fuels. 


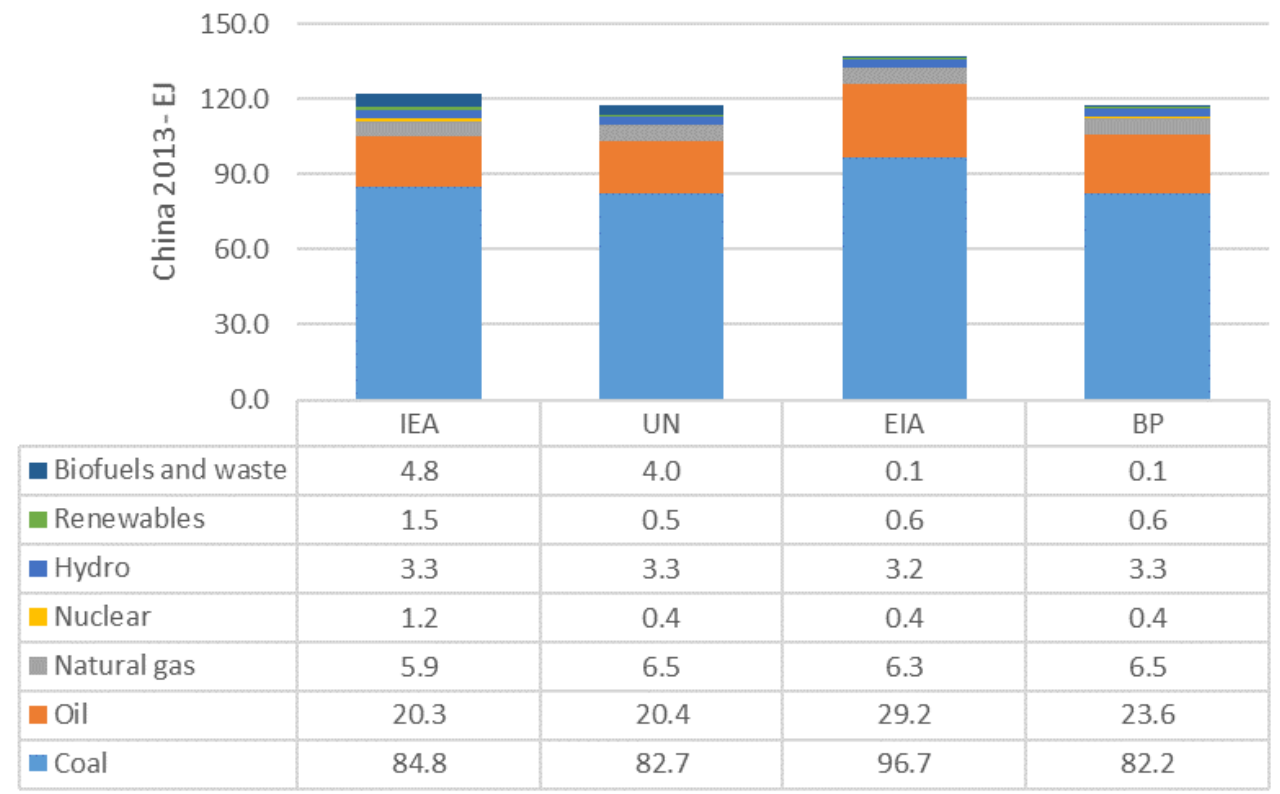

Fig. 3: Total apparent energy consumption by fuel types of China.

\subsection{Uncertainties from Inventory Datasets}

To access the discrepancies for these inventories, global total $\mathrm{CO}_{2}$ emissions data in 2013 reported by 10 inventories are compared as the rest ones are lack of that for 2013. From the global perspective as is shown in figure 4, the discrepancies of global total $\mathrm{CO}_{2}$ emissions in 2013 from these inventories are significant. GCA, CDIAC, and WB inventories report the global total emissions closely. The gap between the maximum (GCB) and minimum values (IEA) is about 4.0 $\mathrm{Pg} \mathrm{CO}_{2} \mathrm{yr}^{-1}$. From the national view in the figure 5, some organizations report the total $\mathrm{CO}_{2}$ emissions of China in 2013 closely such as EIA and BP; CDIAC, GCA, and WB; EDGAR, GCB, and ODIAC. Emissions value of IEA is the smallest and that of ODIAC is the largest. And the gap between them is about $1.5 \mathrm{Pg} \mathrm{CO}_{2} \mathrm{yr}^{-1}$.

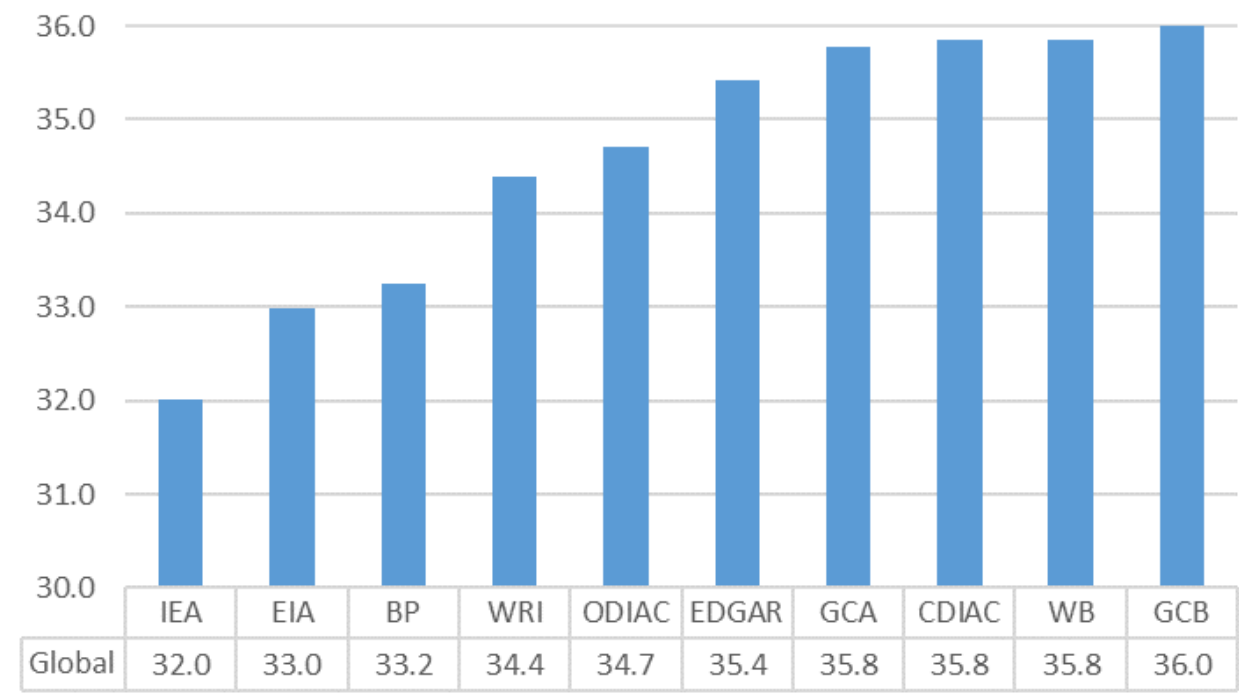

Fig. 4: Global total $\mathrm{CO}_{2}$ emissions in 2013 reported by 10 inventories, unit: $\mathrm{Pg} \mathrm{CO}_{2} \mathrm{yr}^{-1}$.

Comparing with the analysis result for 2005 by Macknick, our result shows that uncertainties in both international energy content and $\mathrm{CO}_{2}$ emissions estimate for the largest emitter nation are increased in 2013. 


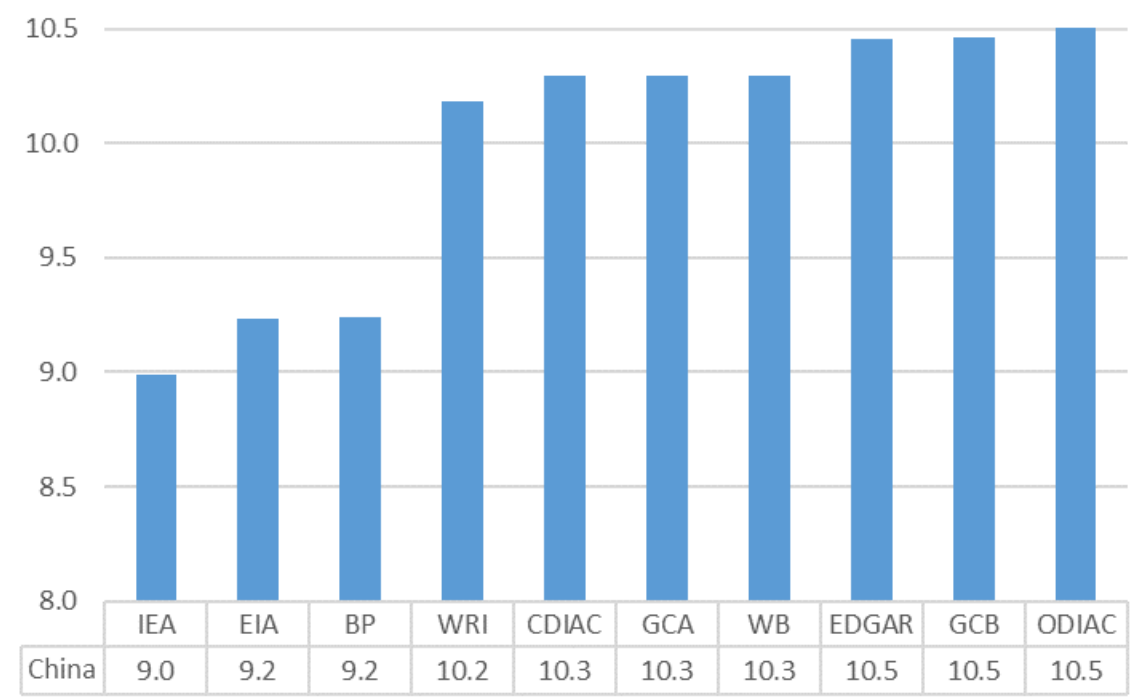

Fig. 5: China total $\mathrm{CO}_{2}$ emissions in 2013 from 10 inventories, $\mathrm{Pg} \mathrm{CO}_{2} \mathrm{yr}^{-1}$

\subsection{Determination for the Nations with Larger Uncertainties in Inventories}

The uncertainties from the datasets across 11 inventories are evaluated by using the reported $\mathrm{CO}_{2}$ emissions for 131 countries in 2008. Other datasets lacking detailed or full national emissions coverage are excluded from our assessment. To show the extent and proportion of uncertainties, standard deviation (SD) and mean percentage of absolute discrepancy (MPAD) are calculated. Applying the equation of mean absolute percentage error [22], MPAD is defined as equation 1. Where $x$ is the name of one dataset, $a$ is the name of one nation, $E_{x, \alpha}$ is the 2008 $\mathrm{CO}_{2}$ emissions for nation $\alpha$ in dataset $x\left(\mathrm{Pg} \mathrm{CO}_{2} \mathrm{yr}^{-1}\right)$, and $M_{a}$ is the mean emissions in 2008 for nation $\alpha$ across $n$ datasets, here $n=11$.

$$
M P A D=\frac{1}{n} \sum\left|\frac{E_{x, a}-M_{a}}{M_{a}}\right|
$$

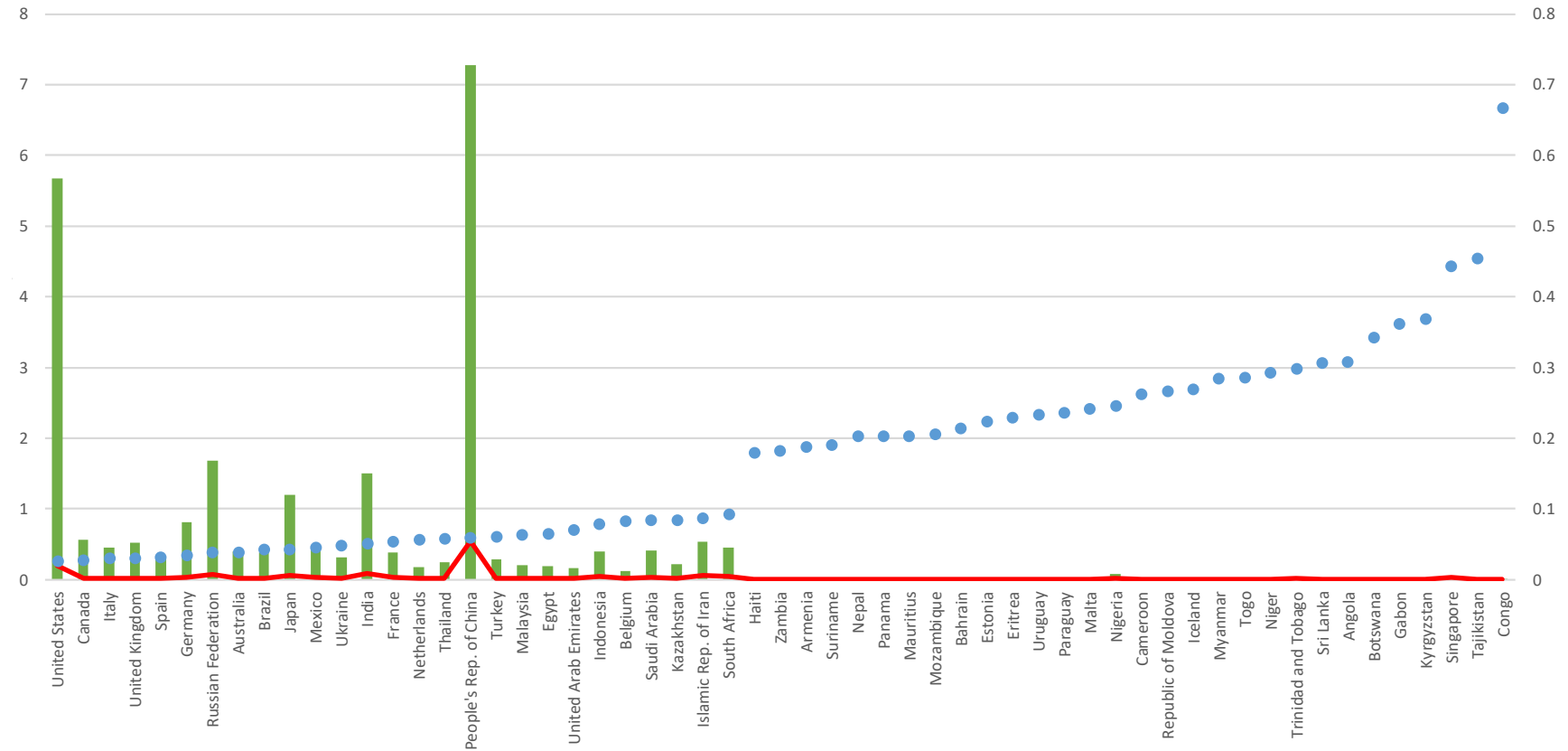

Fig. 6: 57 nations with larger uncertainties of GHG emissions in 2008 across 11 datasets. Referring to the left y-axis, the vertical bar represents mean annual emissions and the line denotes the SD of emissions $\left(\mathrm{Pg} \mathrm{CO}_{2} \mathrm{yr}^{-1}\right)$. While the right $\mathrm{y}$-axis reflects the MPAD from mean annual emissions across all 11 datasets that are showed by the dots. 
In figure 6, nations with larger uncertainties are ranked by MPAD value that are depicted by the dot. The three countries with the largest MPAD are Congo (66.7\%; mean annual $\mathrm{CO}_{2}$ emissions $3.3 \mathrm{E}-3 \mathrm{Pg} \mathrm{CO} \mathrm{Cr}^{-1}$ ), Tajikistan (45.4\%; mean annual $\mathrm{CO}_{2}$ emissions 4.4E-3 $\mathrm{Pg} \mathrm{CO}_{2} \mathrm{yr}^{-1}$ ), and Singapore (44.2\%; mean annual $\mathrm{CO}_{2}$ emissions 4.5E-2 4.5E-2 $\left.\mathrm{Pg} \mathrm{CO}_{2} \mathrm{yr}^{-1}\right)$. Higher MPAD values typically occur in nations with lower total emissions, reflecting a tendency for the proportion of uncertainty among the datasets to increase as total emissions decrease.

For larger emitters, the proportion of uncertainty is smaller yet the SD of uncertainty remains significant. For instance, the three countries with the largest SD of annual emissions are China (MPAD 5.8\%; SD 5.4 $\mathrm{Pg} \mathrm{CO}_{2} \mathrm{yr}^{-1}$ ), the United States (MPAD 2.6\%; SD 1.9 $\mathrm{Pg} \mathrm{CO}_{2} \mathrm{yr}^{-1}$ ), and India (MPAD 5.1\%; SD 0.9 $\mathrm{Pg} \mathrm{CO}_{2} \mathrm{yr}^{-1}$ ). Therefore, to facilitate climate change policy, the proportion and extent of uncertainties in GHG inventories need to be considered together, and particular attention should be paid to the nations with higher standard deviation and proportion values.

\section{Conclusion}

In this paper, 17 datasets used in current global GHG inventories were characterized by four indexes and the uncertainties from that are quantified focusing on two aspects (energy statistics data source and inventory estimation results) in global and national views.

From energy aspect, we found that the global total apparent energy consumption in 2013 contained significate uncertainties and biofuels \& waste consumption owned the largest uncertainties (52.2 EJ between IEA and BP) of all fuels. Among three main fuels, the oil consumption owned the largest uncertainty (44.6 EJ between BP and UN). The gap between maximum (IEA) and minimum (BP) of global total energy consumption was about 24.3 EJ. For largest energy consumer in 2013 China, the coal consumption in which owned the largest uncertainties (15.5 EJ) of all fuels. The gap between maximum (EIA) and minimum (UN) of China total energy consumption was about 18.7 EJ.

From GHG emissions aspect, we found that the global total $\mathrm{CO}_{2}$ emissions in 2013 also owned considerable uncertainties. And the gap between the maximum (GCB) and minimum (IEA) was about $4.0 \mathrm{Pg} \mathrm{CO}_{2} \mathrm{yr}^{-1}$. Some inventories reported global total emissions closely such as GCA, CDIAC and WB. For the largest emitter nation in 2013 China, some organizations reported the total $\mathrm{CO}_{2}$ emissions of China in 2013 closely such as EIA and BP; CDIAC, GCA, and WB; EDGAR, GCB, and ODIAC. And the maximum differences between ODIAC and IEA were about $1.5 \mathrm{Pg} \mathrm{CO}_{2} \mathrm{yr}^{-1}$.

Moreover, 57 nations with larger uncertainties in GHG emissions inventories of 2008 were selected to support the understanding by policymakers. We suggest that more focuses need to be placed on these nations exhibiting higher standard deviation and proportion values and propose that the expertise needed to reduce uncertainties is made more widely available. The uncertainties described above likely result from both the choice of data source and the methodology used to estimate emissions. For example, the use of variable statistical frameworks will increase the uncertainty associated with data sources. Similarly, the use of different emissions factors, accounting methods, and emissions classifications constitute the primary sources of uncertainty in the reporting of data. Therefore, to improve the quality of anthropogenic GHG inventories, investigators need to scrutinize the integrity of their methodology, the completeness of reporting, and procedures for data compilation.

\section{References}

[1] A primer, Prepared by the National Greenhouse Gas Inventories Programme, 2006 IPCC Guidelines for National Greenhouse Gas Inventories, Eggleston H.S., Buendia L., Miwa K., Ngara T. and Tanabe K. eds. IGES, 2008.

[2] T. A. Boden, G. Marland, and R. J. Andres, (2017, May 1). Global, Regional, and National Fossil-Fuel $\mathrm{CO}_{2}$ Emissions. [Online]. Available: http://dx.doi.org/10.3334/CDIAC/00001_V2017

[3] EDGAR, (2018, April 1), Global Emissions EDGAR 24.3.2. [Online]. Available: https://data.europa.eu/doi/10.2904/JRC_DATASET_EDGAR

[4] IEA, (2018, April 1), $\mathrm{CO}_{2}$ Emissions from Fuel Combustion Highlights 2017. [Online]. Available: https://www.iea.org/publications/freepublications/publication/ $\mathrm{CO}_{2}$-emissions-from-fuel-combustion-highlights2017.html

[5] J. Macknick, Energy and carbon dioxide emission data uncertainties, 2009. [Online]. Available: http://pure.iiasa.ac.at/9119

[6] EEA, (2017, May 1), Greenhouse gas emission trends and projections in Europe 2009: Tracking progress towards Kyoto targets. [Online]. Available: http://dx.doi.org/10.2800/23935

[7] FAO, (2018, April 1), FAOSTAT Agri-Environmental Indicators, Emissions by Sector. [Online]. Available: http://www.fao.org/faostat/en/\#data/EM 
[8] FFDAS, (2018, April 1), FFDAS data retrieval. [Online]. Available: http://hpcg.purdue.edu/FFDAS/map.php

[9] Global Carbon Atlas, (2018, April 1), $\mathrm{CO}_{2}$ EMISSIONS. [Online]. Available: http://www.globalcarbonatlas.org/en/content/welcome-carbon-atlas

[10] Global Carbon Project, (2018, April 1), Global Carbon Budget. [Online]. Available: http://www.globalcarbonproject.org/carbonbudget

[11] Regional Emission inventory in Asia, (2018, April 1), Data Download Site. [Online]. Available: https://www.nies.go.jp/REAS

[12] T. Oda, S. Maksyutov, and R. J. Andres, "The Open-source Data Inventory for Anthropogenic $\mathrm{CO}_{2}$, version 2016 (ODIAC2016): a global monthly fossil fuel $\mathrm{CO}_{2}$ gridded emissions data product for tracer transport simulations and surface flux inversions," Earth System Science Data, vol. 10, no. 1, pp. 87-107. [Online]. Available: https://doi.org/10.5194/essd-10-87-2018

[13] OECD, (2018, April 1), GHG emissions. [Online]. Available: http://www.compareyourcountry.org/climatepolicies?cr $=$ oecd \&lg $=$ en\&page $=1 \&$ visited $=1 \#$

[14] PBL Netherlands Environmental Assessment Agency, (2018, April 1), Trend in global $\mathrm{CO}_{2}$ emissions. [Online]. Available: http://www.pbl.nl/en/trends-in-global- $\mathrm{CO}_{2}$-emissions

[15] PKU, (2018, April 1), PKU-Inventory [Online]. Available: http://inventory.pku.edu.cn/home.html

[16] WB, (2018, April 1), $\mathrm{CO}_{2} \quad$ emissions. [Online]. Available: https://data.worldbank.org/indicator/EN.ATM.CO2E.KT

[17] CAIT, (2017, May 1), CAIT Climate Data Explorer. [Online]. Available: http://cait.wri.org

[18] IEA, (2018, April 1), Statistics Search. [Online]. Available: http://www.iea.org/statistics/statisticssearch

[19] EIA, (2018, April 1), International Energy Statistics. [Online]. Available: https://www.eia.gov/beta/international

[20] UN, (2016), 2014 Energy Statistics Yearbook. [Online]. Available: https://unstats.un.org/unsd/energy

[21] BP, (2018, April 1), BP Statistics Review of World Energy June 2017, 66th ed. [Online]. Available: https://www.bp.com

[22] S. Kim and H. Kim, "A new metric of absolute percentage error for intermittent demand forecasts," International Journal of Forecasting, vol. 32, no. 3, pp. 669-679, 2016. 